\title{
Hybrid iterative algorithms for nonexpansive and nonspreading mappings in Hilbert spaces
}

\section{Shenghua Wang*}

\section{"Correspondence:}

sheng-huawang@hotmail.com School of Mathematics and Physics, North China Electric Power University, Baoding, 071003, P.R China

\begin{abstract}
Recently, lemoto and Takahashi considered a weak convergence iterative scheme for a nonspreading mapping and a nonexpansive mapping in Hilbert spaces. In this paper, we suggest two hybrid iterative algorithms by modifying lemoto and Takahashi's iterative scheme for a countable family of nonspreading mappings and a nonexpansive mapping in Hilbert spaces.
\end{abstract}

MSC: $47 \mathrm{H} 05 ; 47 \mathrm{H} 09$

Keywords: nonexpansive mappings; nonspreading mappings; AKTT-condition; hybrid algorithms

\section{Introduction and preliminaries}

Let $H$ be a Hilbert space and $C$ be a nonempty closed convex subset of $H$. Let $T$ be a nonlinear mapping of $C$ into itself. We use $F(T)$ and $P_{C}$ to denote the set of fixed points of $T$ and the metric projection from $H$ onto $C$, respectively.

Recall that $T$ is said to be nonexpansive if

$$
\|T x-T y\| \leq\|x-y\|
$$

for all $x, y \in C$.

For approximating the fixed point of a nonexpansive mapping in a Hilbert space, Mann [1] in 1953 introduced the famous iterative scheme as follows:

$$
\forall x_{1} \in C, \quad x_{n+1}=\left(1-\alpha_{n}\right) x_{n}+\alpha_{n} T x_{n}, \quad \forall n \geq 1,
$$

where $T$ is a nonexpansive mapping of $C$ into itself and $\left\{\alpha_{n}\right\}$ is a sequence in $(0,1)$. It is well known that $\left\{x_{n}\right\}$ defined in (1.2) converges weakly to a fixed point of $T$.

Attempts to modify the normal Mann iteration method (1.2) for nonexpansive mappings so that strong convergence is guaranteed have recently been made; see, e.g., [2-9].

Let $T$ be a mapping from $C$ into itself. Then $T$ is called nonspreading [3] if

$$
2\|T x-T y\|^{2} \leq\|T x-y\|^{2}+\|x-T y\|^{2}
$$

for all $x, y \in C$. A mapping $T: C \rightarrow C$ is called quasi-nonexpansive if $F(T) \neq \varnothing$ and $\| T x-$ $y\|\leq\| x-y \|$ for all $x \in C$ and $y \in F(T)$. If $T$ is a nonspreading mapping from $C$ into itself

\section{Springer}

C2013 Wang: licensee Springer. This is an Open Access article distributed under the terms of the Creative Commons Attribution License (http://creativecommons.org/licenses/by/2.0), which permits unrestricted use, distribution, and reproduction in any medium, provided the original work is properly cited. 
and $F(T)$ is nonempty, then $T$ is quasi-nonexpansive. Further, we know that the set of fixed points of each quasi-nonexpansive mapping is closed and convex; see [10].

In [11], by using Moudafi's iterative scheme [12], Iemoto and Takahashi considered the following weak convergence theorem.

Theorem IT ([11]) Let H be a Hilbert space, and let $C$ be a nonempty closed convex subset of $H$. Let $S$ be a nonspreading mapping of $C$ into itself, and let $T$ be a nonexpansive mapping of $C$ into itself such that $F(S) \cap F(T) \neq \emptyset$. Define a sequence $\left\{x_{n}\right\}$ as follows:

$$
\left\{\begin{array}{l}
x_{1} \in C, \\
x_{n+1}=\left(1-\alpha_{n}\right) x_{n}+\alpha_{n}\left\{\beta_{n} S x_{n}+\left(1-\beta_{n}\right) T x_{n}\right\}
\end{array}\right.
$$

for all $n \in N$, where $\left\{\alpha_{n}\right\},\left\{\beta_{n}\right\} \subset[0,1]$. Then the following hold:

(i) If $\liminf _{n \rightarrow \infty} \alpha_{n}\left(1-\alpha_{n}\right)>0$ and $\sum_{n=1}^{\infty}\left(1-\beta_{n}\right)<\infty$, then $\left\{x_{n}\right\}$ converges weakly to $v \in F(S)$;

(ii) If $\sum_{i=1}^{\infty} \alpha_{n}\left(1-\alpha_{n}\right)=\infty$ and $\sum_{n=1}^{\infty} \beta_{n}<\infty$, then $\left\{x_{n}\right\}$ converges weakly to $v \in F(T)$;

(iii) If $\liminf _{n \rightarrow \infty} \alpha_{n}\left(1-\alpha_{n}\right)>0$ and $\liminf _{n \rightarrow \infty} \beta_{n}\left(1-\beta_{n}\right)>0$, then $\left\{x_{n}\right\}$ converges weakly to $v \in F(S) \cap F(T)$.

In this paper, we modify (1.1) by a hybrid iterative scheme and obtain the strong convergence theorems for a family of nonspreading mappings and a nonexpansive mapping in a Hilbert space.

Let $E$ be a Banach space and $K$ be a nonempty closed convex subset of $E$. Let $\left\{T_{n}\right\}: K \rightarrow$ $K$ be a family of mappings. Then $\left\{T_{n}\right\}$ is said to satisfy the AKTT-condition [13] if for each bounded subset $B$ of $K$, one has

$$
\sum_{n=1}^{\infty} \sup \left\{\left\|T_{n+1} z-T_{n} z\right\|: z \in B\right\}<\infty
$$

The following is an important result on a family of mappings $\left\{T_{n}\right\}_{n=1}^{\infty}$ satisfying the AKTT-condition.

Lemma 1.1 ([13]) Let $K$ be a nonempty and closed subset of a Banach space E, and let $\left\{T_{n}\right\}_{n=1}^{\infty}$ be a family of mappings of $K$ into itself which satisfies the AKTT-condition. Then, for each $x \in K,\left\{T_{n} x\right\}$ converges strongly to a point in K. Moreover, let the mapping $T: K \rightarrow K$ be defined by

$$
T x=\lim _{n \rightarrow \infty} T_{n} x, \quad \forall x \in K .
$$

Then, for each bounded subset $B$ of $K$,

$$
\limsup _{n \rightarrow \infty}\left\{\left\|T z-T_{n} z\right\|: z \in B\right\}=0
$$

Obviously, if a family of mappings $\left\{T_{n}\right\}_{n=1}^{\infty}$ satisfies the AKTT-condition and $T x=$ $\lim _{n \rightarrow \infty} T_{n} x$ for each $x \in K$, then it is unnecessary that $F(T)=\bigcap_{i=1}^{\infty} F\left(T_{i}\right)$. To show this, see the following example. 
Example 1.1 Let $E=\mathbb{R}$ and $K=[0,2]$. Define a family of mappings $\left\{T_{n}\right\}_{n=1}^{\infty}: K \rightarrow K$ by

$$
T_{1} x=0, \quad T_{n}=\frac{1}{n}(1+x), \quad n \geq 2 .
$$

Then $\left\{T_{n}\right\}_{n=1}^{\infty}$ satisfy the AKTT-condition. It is easy to see that for each $x \in K, \lim _{n \rightarrow \infty} T_{n} \times$ $x=0$. Define the mapping $T: K \rightarrow K$ by $T x=\lim _{n \rightarrow \infty} T_{n} x$. That is, $T x=0$ for all $x \in K$. But $F(T) \neq \bigcap_{n=1}^{\infty} F\left(T_{n}\right)$.

In this paper, we call that $\left\{T_{n}, T\right\}$ satisfy the AKTT-condition if $\left\{T_{n}\right\}_{n=1}^{\infty}$ satisfy the AKTTcondition with $F(T)=\bigcap_{n=1}^{\infty} F\left(T_{n}\right)$.

Lemma 1.2 ([11]) Let C be a nonempty closed subset of a Hilbert space H. Then a mapping $T: C \rightarrow C$ is nonspreading if and only if

$$
\|T x-T y\|^{2} \leq\|x-y\|^{2}+2\langle x-T x, y-T y\rangle
$$

for all $x, y \in C$.

By using Lemma 1.2, we get the following simple but important result.

Lemma 1.3 Let $H$ be a Hilbert space and $C$ be a nonempty subset of $H$. Let $\left\{T_{n}\right\}$ be a family of nonspreading mappings of $C$ into itself, and assume that $\lim _{n \rightarrow \infty} T_{n} x$ exists for each $x \in C$. Define the mapping $T: C \rightarrow C$ by $T x=\lim _{n \rightarrow \infty} T_{n} x$. Then the mapping $T$ is a nonspreading mapping.

Proof In fact, for all $x, y \in C$, we have

$$
\begin{aligned}
\|T x-T y\|^{2} & =\left\|\lim _{n \rightarrow \infty} T_{n} x-\lim _{n \rightarrow \infty} T_{n} y\right\|^{2} \\
& =\lim _{n \rightarrow \infty}\left\|T_{n} x-T_{n} y\right\|^{2} \\
& \leq \lim _{n \rightarrow \infty}\left[\|x-y\|^{2}+2\left\langle x-T_{n} x, y-T_{n} y\right\rangle\right] \\
& =\|x-y\|^{2}+2\left\langle x-\lim _{n \rightarrow \infty} T_{n} x, y-\lim _{n \rightarrow \infty} T_{n} y\right\rangle \\
& =\|x-y\|^{2}+2\langle x-T x, y-T y\rangle .
\end{aligned}
$$

Lemma 1.2 shows that the mapping $T$ is a nonspreading mapping.

Lemma 1.4 Let $C$ be a closed convex subset of a real Hilbert space $H$, and let $P_{C}$ be the metric projection from $H$ onto $C$ (i.e., for $x \in H, P_{C} x$ is the only point in $C$ such that $\| x-$ $\left.P_{C} x \|=\inf \{\|x-z\|: z \in C\}\right)$. Given $x \in H$ and $z \in C$. Then $z=P_{C} x$ if and only if the following relation holds:

$$
\langle x-z, y-z\rangle \leq 0, \quad \forall y \in C
$$

Lemma 1.5 ([14]) Let $H$ be a real Hilbert space. Then the following equation holds:

$$
\|t x+(1-t) y\|^{2}=t\|x\|^{2}+(1-t)\|y\|^{2}-t(1-t)\|x-y\|^{2}, \quad \forall x \in C \text { and } \forall t \in[0,1] .
$$




\section{Main results}

Theorem 2.1 Let $C$ be a nonempty closed convex subset of a Hilbert space H. Let $S: C \rightarrow C$ be a nonexpansive mapping and $\left\{T_{i}\right\}_{i=1}^{\infty}: C \rightarrow C$ be a countable family of nonspreading mappings such that $F=F(S) \cap\left[\bigcap_{i=1}^{\infty} F\left(T_{i}\right)\right] \neq \emptyset$. Let $\left\{x_{n}\right\}$ be a sequence generated in the following manner:

$$
\left\{\begin{array}{l}
x_{1}=x \in C \quad \text { chosen arbitrarily, } \\
y_{n}=\left(1-\alpha_{n}\right) x_{n}+\alpha_{n}\left[\beta_{n} S x_{n}+\sum_{i=1}^{n}\left(\beta_{i-1}-\beta_{i}\right) T_{i} x_{n}\right], \\
C_{n}=\left\{v \in C:\left\|y_{n}-v\right\| \leq\left\|x_{n}-v\right\|\right\}, \\
D_{n}=\bigcap_{j=1}^{n} C_{j}, \\
x_{n+1}=P_{D_{n}} x, \quad n \geq 1,
\end{array}\right.
$$

where $\left\{\alpha_{n}\right\},\left\{\beta_{n}\right\} \subset[0,1]$. Assume that $\left\{\beta_{n}\right\}$ is strictly decreasing and $\beta_{0}=1$. Then the following hold:

(i) If $\liminf _{n \rightarrow \infty} \alpha_{n}>0$ and $\lim _{n \rightarrow \infty} \beta_{n}=0$, then $\left\{x_{n}\right\}$ strongly converges to $q \in \bigcap_{i=1}^{\infty} F\left(T_{i}\right)$

(ii) If $\liminf _{n \rightarrow \infty} \alpha_{n}\left(1-\alpha_{n}\right)>0$ and $\liminf _{n \rightarrow \infty} \beta_{n}>0$, then $\left\{x_{n}\right\}$ converges strongly to $q \in F$.

Proof Obviously, each $C_{n}$ is closed and convex and hence $D_{n}$ is closed and convex. Next, we show that $F \subset D_{n}$ for all $n \geq 1$. To end this, we need to prove that $F \subset C_{n}$ for all $n \geq 1$. Indeed, for each $p \in F$, we have

$$
\begin{aligned}
\left\|y_{n}-p\right\| & \leq\left(1-\alpha_{n}\right)\left\|x_{n}-p\right\|+\alpha_{n}\left[\beta_{n}\left\|S x_{n}-p\right\|+\sum_{i=1}^{n}\left(\beta_{i-1}-\beta_{i}\right)\left\|T_{i} x_{n}-p\right\|\right] \\
& \leq\left(1-\alpha_{n}\right)\left\|x_{n}-p\right\|+\alpha_{n}\left[\beta_{n}\left\|x_{n}-p\right\|+\sum_{i=1}^{n}\left(\beta_{i-1}-\beta_{i}\right)\left\|x_{n}-p\right\|\right] \\
& =\left\|x_{n}-p\right\| .
\end{aligned}
$$

This implies that

$$
p \in C_{n} \text { for all } n \geq 1 .
$$

Therefore, $F \subset C_{n}$ and hence $C_{n}$ is nonempty for all $n \geq 1$. On the other hand, from the definition of $D_{n}$, we see that $F \subset D_{n}=\bigcap_{i=1}^{n} C_{j}$ for all $n \geq 1$.

From $x_{n+1}=P_{D_{n}} x$, we have

$$
\left\|x_{n+1}-x\right\| \leq\|v-x\|, \quad \forall v \in D_{n}, n \geq 1 .
$$

Since $P_{F} x \in F \subset D_{n}$, one has

$$
\left\|x_{n+1}-x\right\| \leq\left\|P_{F} x-x\right\|, \quad n \geq 1
$$

This implies that $\left\{x_{n}\right\}$ is bounded and hence $\left\{y_{n}\right\}$ is bounded. 
On the other hand, since $D_{n+1} \subset D_{n}$ for all $n \geq 1$, we have

$$
x_{n+2}=P_{D_{n+1}} x \in D_{n+1} \subset D_{n}
$$

for all $n \geq 1$. From $x_{n+1}=P_{D_{n}} x$ one has

$$
\left\|x_{n+1}-x\right\| \leq\left\|x_{n+2}-x\right\|
$$

for all $n \geq 1$. It follows from (2.3) and (2.4) that the limit of $\left\{x_{n}-x\right\}$ exists.

Since $D_{m} \subset D_{n}$ and $x_{m+1}=P_{D_{m}} x \in D_{m} \subset D_{n}$ for all $m \geq n$ and $x_{n+1}=P_{D_{n}} x$, by Lemma 1.4 one has

$$
\left\langle x_{n+1}-x, x_{m+1}-x_{n+1}\right\rangle \geq 0 .
$$

It follows from $(2.5)$ that

$$
\begin{aligned}
& \left\|x_{m+1}-x_{n+1}\right\|^{2} \\
& \quad=\left\|x_{m+1}-x-\left(x_{n+1}-x\right)\right\|^{2} \\
& \quad=\left\|x_{m+1}-x\right\|^{2}+\left\|x_{n+1}-x\right\|^{2}-2\left\langle x_{n+1}-x, x_{m+1}-x\right\rangle \\
& \quad=\left\|x_{m+1}-x\right\|^{2}+\left\|x_{n+1}-x\right\|^{2}-2\left\langle x_{n+1}-x, x_{m+1}-x_{n+1}+x_{n+1}-x\right\rangle \\
& \quad=\left\|x_{m+1}-x\right\|^{2}-\left\|x_{n+1}-x\right\|^{2}-2\left\langle x_{n+1}-x, x_{m+1}-x_{n+1}\right\rangle \\
& \quad \leq\left\|x_{m+1}-x\right\|^{2}-\left\|x_{n+1}-x\right\|^{2} .
\end{aligned}
$$

Since the limit of $\left\|x_{n}-x\right\|$ exists, we get

$$
\lim _{m, n \rightarrow \infty}\left\|x_{m}-x_{n}\right\|=0
$$

It follows that $\left\{x_{n}\right\}$ is a Cauchy sequence. Since $H$ is a Hilbert space and $C$ is closed and convex, there exists $q \in C$ such that

$$
x_{n} \rightarrow q, \quad \text { as } n \rightarrow \infty \text {. }
$$

By taking $m=n+1$ in (2.6), one arrives at

$$
\lim _{n \rightarrow \infty}\left\|x_{n+2}-x_{n+1}\right\|=0
$$

i.e.,

$$
\lim _{n \rightarrow \infty}\left\|x_{n+1}-x_{n}\right\|=0 .
$$

Noticing that $x_{n+1}=P_{D_{n}} x \in D_{n} \subset C_{n}$, we get

$$
\left\|y_{n}-x_{n+1}\right\| \leq\left\|x_{n}-x_{n+1}\right\| \rightarrow 0,
$$


and hence

$$
\left\|y_{n}-x_{n}\right\| \leq\left\|y_{n}-x_{n+1}\right\|+\left\|x_{n+1}-x_{n}\right\| \rightarrow 0 \text {. }
$$

From (2.7) and (2.9) it follows that

$$
\lim _{n \rightarrow \infty}\left\|y_{n}-p\right\|=\lim _{n \rightarrow \infty}\left\|x_{n}-p\right\|=\|q-p\|, \quad \forall p \in F
$$

Now we prove (i). Note that

$$
\begin{aligned}
y_{n} & =\left(1-\alpha_{n}\right) x_{n}+\alpha_{n}\left[\beta_{n} S x_{n}+\sum_{i=1}^{n}\left(\beta_{i-1}-\beta_{i}\right)\left(T_{i} x_{n}-x_{n}\right)\right]+\alpha_{n}\left(1-\beta_{n}\right) x_{n} \\
& =\left(1-\alpha_{n} \beta_{n}\right) x_{n}+\alpha_{n} \beta_{n} S x_{n}+\alpha_{n} \sum_{i=1}^{n}\left(\beta_{i-1}-\beta_{i}\right)\left(T_{i} x_{n}-x_{n}\right) .
\end{aligned}
$$

Hence,

$$
\alpha_{n} \sum_{i=1}^{n}\left(\beta_{i-1}-\beta_{i}\right)\left(T_{i} x_{n}-x_{n}\right)=\left(1-\alpha_{n} \beta_{n}\right)\left(y_{n}-x_{n}\right)+\alpha_{n} \beta_{n}\left(y_{n}-S x_{n}\right) .
$$

On the other hand, for any $p \in F$, from Lemma 1.2 we have

$$
\begin{aligned}
\left\|x_{n}-p\right\|^{2} & =2\left\langle x_{n}-T_{i} x_{n}, p-T_{i} p\right\rangle+\left\|x_{n}-p\right\|^{2} \\
& \geq\left\|T_{i} x_{n}-T_{i} p\right\|^{2}=\left\|T_{i} x_{n}-p\right\|^{2}=\left\|T_{i} x_{n}-x_{n}+\left(x_{n}-p\right)\right\|^{2} \\
& =\left\|T_{i} x_{n}-x_{n}\right\|^{2}+\left\|x_{n}-p\right\|^{2}+2\left\langle T_{i} x_{n}-x_{n}, x_{n}-p\right\rangle,
\end{aligned}
$$

and hence

$$
\left\|T_{i} x_{n}-x_{n}\right\|^{2} \leq 2\left\langle x_{n}-T_{i} x_{n}, x_{n}-p\right\rangle, \quad \forall i \in \mathbb{N} .
$$

Note that $\left\{\beta_{n}\right\}$ is strictly decreasing. Hence from (2.11) and (2.12) we get

$$
\begin{aligned}
\left\|T_{i} x_{n}-x_{n}\right\|^{2} \leq & \frac{1}{2 \alpha_{n}\left(\beta_{i-1}-\beta_{i}\right)}\left[\left(1-\alpha_{n} \beta_{n}\right)\left\langle y_{n}-x_{n}, x_{n}-T_{i} p\right\rangle\right. \\
& \left.+\alpha_{n} \beta_{n}\left\langle y_{n}-S x_{n}, x_{n}-p\right\rangle\right], \quad i \geq 1 .
\end{aligned}
$$

Since $\liminf \operatorname{in}_{n \rightarrow \infty} \alpha_{n}>0$ and $\lim _{n \rightarrow \infty} \beta_{n}=0$, from (2.9) and (2.13) it follows that

$$
\lim _{n \rightarrow \infty}\left\|T_{i} x_{n}-x_{n}\right\|=0, \quad \forall i \in \mathbb{N} .
$$

Since each $T_{i}$ is a nonspreading mapping, by Lemma 1.2, (2.7) and (2.10), we have

$$
\left\|T_{i} q-T_{i} x_{n}\right\|^{2} \leq\left\|x_{n}-q\right\|^{2}+2\left\langle q-T_{i} q, x_{n}-T_{i} x_{n}\right\rangle \rightarrow 0, \quad \forall i \in \mathbb{N} .
$$

Further, one has

$$
\left\|q-T_{i} q\right\| \leq\left\|q-x_{n}\right\|+\left\|x_{n}-T_{i} x_{n}\right\|+\left\|T_{i} x_{n}-T_{i} q\right\| \rightarrow 0, \quad \forall i \in \mathbb{N} .
$$

So, we have $q \in \bigcap_{i=1}^{\infty} F\left(T_{i}\right)$. 
To prove (ii), first we show that $\lim _{n \rightarrow \infty}\left\|x_{n}-S x_{n}\right\|=0$. For any $p \in F$, we have

$$
\begin{aligned}
\left\|y_{n}-p\right\|^{2}= & \left\|\beta_{n}\left[\left(1-\alpha_{n}\right) x_{n}+\alpha_{n} S x_{n}-p\right]+\sum_{i=1}^{n}\left(\beta_{i-1}-\beta_{i}\right)\left[\left(1-\alpha_{n}\right) x_{n}+\alpha_{n} T_{i} x_{n}-p\right]\right\|^{2} \\
\leq & \beta_{n}\left\|\left(1-\alpha_{n}\right) x_{n}+\alpha_{n} S x_{n}-p\right\|^{2}+\sum_{i=1}^{n}\left(\beta_{i-1}-\beta_{i}\right)\left\|\left(1-\alpha_{n}\right) x_{n}+\alpha_{n} T_{i} x_{n}-p\right\|^{2} \\
\leq & \beta_{n}\left\|\left(1-\alpha_{n}\right) x_{n}+\alpha_{n} S x_{n}-p\right\|^{2} \\
& +\sum_{i=1}^{n}\left(\beta_{i-1}-\beta_{i}\right)\left[\left(1-\alpha_{n}\right)\left\|x_{n}-p\right\|^{2}+\alpha_{n}\left\|T_{i} x_{n}-p\right\|^{2}\right] \\
\leq & \beta_{n}\left\|\left(1-\alpha_{n}\right) x_{n}+\alpha_{n} S x_{n}-p\right\|^{2}+\sum_{i=1}^{n}\left(\beta_{i-1}-\beta_{i}\right)\left\|x_{n}-p\right\|^{2} \\
= & \beta_{n}\left\|\left(1-\alpha_{n}\right) x_{n}+\alpha_{n} S x_{n}-p\right\|^{2}+\left(1-\beta_{n}\right)\left\|x_{n}-p\right\|^{2} \\
\leq & \left\|x_{n}-p\right\|^{2},
\end{aligned}
$$

and hence by (2.10) we get

$$
\begin{aligned}
0 & \leq\left\|x_{n}-p\right\|^{2}-\beta_{n}\left\|\left(1-\alpha_{n}\right) x_{n}+\alpha_{n} S x_{n}-p\right\|^{2}-\left(1-\beta_{n}\right)\left\|x_{n}-p\right\|^{2} \\
& =\beta_{n}\left[\left\|x_{n}-p\right\|^{2}-\left\|\left(1-\alpha_{n}\right) x_{n}+\alpha_{n} S x_{n}-p\right\|^{2}\right] \\
& \leq\left\|x_{n}-p\right\|^{2}-\left\|y_{n}-p\right\|^{2} \rightarrow 0 .
\end{aligned}
$$

Since $\liminf _{n \rightarrow \infty} \beta_{n}>0$, it follows from (2.17) that

$$
\lim _{n \rightarrow \infty}\left(\left\|x_{n}-p\right\|^{2}-\left\|\left(1-\alpha_{n}\right) x_{n}+\alpha_{n} S x_{n}-p\right\|^{2}\right)=0 .
$$

From (2.18) and

$$
\left\|\left(1-\alpha_{n}\right) x_{n}+\alpha_{n} S x_{n}-p\right\|^{2}=\left(1-\alpha_{n}\right)\left\|x_{n}-p\right\|^{2}+\alpha_{n}\left\|S x_{n}-p\right\|^{2}-\alpha_{n}\left(1-\alpha_{n}\right)\left\|x_{n}-S x_{n}\right\|^{2},
$$

we get

$$
\begin{aligned}
& \alpha_{n}\left(1-\alpha_{n}\right)\left\|x_{n}-S x_{n}\right\|^{2} \\
& \quad=\left(\left\|x_{n}-p\right\|^{2}-\left\|\left(1-\alpha_{n}\right) x_{n}+\alpha_{n} S x_{n}-p\right\|^{2}\right)-\alpha_{n}\left\|x_{n}-p\right\|^{2}+\alpha_{n}\left\|S x_{n}-p\right\|^{2} \\
& \quad \leq\left(\left\|x_{n}-p\right\|^{2}-\left\|\left(1-\alpha_{n}\right) x_{n}+\alpha_{n} S x_{n}-p\right\|^{2}\right)-\alpha_{n}\left\|x_{n}-p\right\|^{2}+\alpha_{n}\left\|x_{n}-p\right\|^{2} \\
& \quad=\left\|x_{n}-p\right\|^{2}-\left\|\left(1-\alpha_{n}\right) x_{n}+\alpha_{n} S x_{n}-p\right\|^{2} \rightarrow 0 .
\end{aligned}
$$

Since $\liminf _{n \rightarrow \infty} \alpha_{n}\left(1-\alpha_{n}\right)>0$, we get

$$
\lim _{n \rightarrow \infty}\left\|x_{n}-S x_{n}\right\|=0
$$

Now, using (2.19), (2.7) and

$$
\|q-S q\| \leq\left\|q-x_{n}\right\|+\left\|x_{n}-S x_{n}\right\|+\left\|S x_{n}-S q\right\| \leq 2\left\|q-x_{n}\right\|+\left\|x_{n}-S x_{n}\right\| \rightarrow 0,
$$

which implies that $q \in F(S)$. 
Note that (2.9) and (2.19) imply that $\lim _{n \rightarrow \infty}\left\|y_{n}-S x_{n}\right\|=0$. Then, repeating (2.11) to (2.16), we get $q \in \bigcap_{i=1}^{\infty} F\left(T_{i}\right)$. So, $q \in F$. This completes the proof.

Theorem 2.2 Let $C$ be a nonempty closed convex subset of a Hilbert space H. Let $S: C \rightarrow C$ be a nonexpansive mapping and $\left\{T_{i}\right\}_{i=1}^{\infty}: C \rightarrow C$ be a countable family of nonspreading mappings such that $F=F(S) \cap\left[\bigcap_{i=1}^{\infty} F\left(T_{i}\right)\right] \neq \emptyset$. Let $\left\{x_{n}\right\}$ be a sequence generated in the following manner:

$$
\left\{\begin{array}{l}
x_{1}=x \in C \quad \text { chosen arbitrarily, } \\
y_{n}=\left(1-\alpha_{n}\right) x_{n}+\alpha_{n}\left[\beta_{n} S x_{n}+\left(1-\beta_{n}\right) T_{n} x_{n}\right], \\
C_{n}=\left\{v \in C:\left\|y_{n}-v\right\| \leq\left\|x_{n}-v\right\|\right\}, \\
D_{n}=\bigcap_{j=1}^{n} C_{j}, \\
x_{n+1}=P_{D_{n}} x, \quad n \geq 1,
\end{array}\right.
$$

where $\left\{\alpha_{n}\right\},\left\{\beta_{n}\right\} \subset[0,1]$. Assume that $\left\{T_{n}, T\right\}$ satisfies the AKTT-condition. Then the following hold:

(i) If $\liminf _{n \rightarrow \infty} \alpha_{n}>0$ and $\lim _{n \rightarrow \infty} \beta_{n}=0$, then $\left\{x_{n}\right\}$ strongly converges to $v \in \bigcap_{i=1}^{\infty} F\left(T_{i}\right)$;

(ii) If $\liminf _{n \rightarrow \infty} \alpha_{n}\left(1-\alpha_{n}\right)>0$ and $\liminf _{n \rightarrow \infty} \beta_{n}>0$, then $\left\{x_{n}\right\}$ converges strongly to $z \in F$.

Proof By a process similar to the proof of Theorem 2.1, we can conclude that $\left\{x_{n}\right\}$ converges strongly to some $q \in C$ and

$$
x_{n}-y_{n} \rightarrow 0 \text {. }
$$

We first prove (i). From (2.20) we have

$$
T_{n} x_{n}-x_{n}=\frac{1}{\alpha_{n}\left(1-\beta_{n}\right)}\left(y_{n}-x_{n}\right)-\frac{\beta_{n}}{1-\beta_{n}}\left(S x_{n}-x_{n}\right),
$$

and hence

$$
\left\|T_{n} x_{n}-x_{n}\right\| \leq \frac{1}{\alpha_{n}\left(1-\beta_{n}\right)}\left\|y_{n}-x_{n}\right\|+\frac{\beta_{n}}{1-\beta_{n}}\left\|S x_{n}-x_{n}\right\| .
$$

Since $\liminf _{n \rightarrow \infty} \alpha_{n}>0$ and $\lim _{n \rightarrow \infty} \beta_{n}=0$, we get

$$
\lim _{n \rightarrow \infty}\left\|T_{n} x_{n}-x_{n}\right\|=0
$$

Further, by Lemma 1.1 and (2.21), we have

$$
\begin{aligned}
\left\|x_{n}-T x_{n}\right\| & \leq\left\|x_{n}-T_{n} x_{n}\right\|+\left\|T_{n} x_{n}-T x_{n}\right\| \\
& \leq\left\|x_{n}-T_{n} x_{n}\right\|+\sup \left\{\left\|T_{n} z-T z\right\|: z \in\left\{x_{n}\right\}\right\} \rightarrow 0 .
\end{aligned}
$$

Since each $T_{n}$ is a nonspreading mapping, Lemma 1.3 shows that $T$ is a nonspreading mapping. Further, by using Lemma 1.2, we have

$$
\left\|T q-T x_{n}\right\|^{2} \leq\left\|x_{n}-q\right\|^{2}+2\left\langle q-T q, x_{n}-T x_{n}\right\rangle \rightarrow 0, \quad \forall i \in \mathbb{N} .
$$


From (2.21) and (2.23) it follows that

$$
\|q-T q\| \leq\left\|q-x_{n}\right\|+\left\|x_{n}-T x_{n}\right\|+\left\|T x_{n}-T q\right\| \rightarrow 0
$$

It follows that $q \in F(T)$. Since $\left(\left\{T_{n}\right\}, T\right)$ satisfies the AKTT-condition, one has $q \in$ $\bigcap_{i=1}^{\infty} F\left(T_{i}\right)=F(T)$. This completes (i).

Next we show (ii). By a process similar to the proof of Theorem 2.1 and from (2.22) to (2.24), we can get that

$$
\begin{aligned}
& \lim _{n \rightarrow \infty}\left\|x_{n}-S x_{n}\right\|=0, \quad \lim _{n \rightarrow \infty}\left\|x_{n}-T_{n} x_{n}\right\|=0, \\
& \lim _{n \rightarrow \infty}\left\|T x_{n}-T q\right\|=0 \quad \text { and } \quad \lim _{n \rightarrow \infty}\left\|x_{n}-T x_{n}\right\|=0 .
\end{aligned}
$$

Finally, by

$$
\|q-S q\| \leq\left\|q-x_{n}\right\|+\left\|x_{n}-S x_{n}\right\|+\left\|S x_{n}-S q\right\| \leq 2\left\|x_{n}-q\right\|+\left\|x_{n}-S x_{n}\right\| \rightarrow 0
$$

and

$$
\|q-T q\| \leq\left\|q-x_{n}\right\|+\left\|x_{n}-T x_{n}\right\|+\left\|T x_{n}-T q\right\| \rightarrow 0,
$$

we get $q \in F(S) \cap F(T)$. Since $\left(\left\{T_{n}\right\}, T\right)$ satisfies the AKTT-condition, we conclude that $q \in F$. This completes (ii).

Letting $T_{i}=T$ for all $i \in \mathbb{N}$ in Theorem 2.1 and Theorem 2.2, we get the following corollary.

Corollary 2.1 Let C be a nonempty closed convex subset of a Hilbert space H. Let $S: C \rightarrow C$ be a nonexpansive mapping and $T: C \rightarrow C$ be a nonspreading mapping such that $F(S) \cap$ $F(T) \neq \emptyset$. Let $\left\{x_{n}\right\}$ be a sequence generated in the following manner:

$$
\left\{\begin{array}{l}
x_{1}=x \in C \quad \text { chosen arbitrarily, } \\
y_{n}=\left(1-\alpha_{n}\right) x_{n}+\alpha_{n}\left[\beta_{n} S x_{n}+\left(1-\beta_{n}\right) T x_{n}\right], \\
C_{n}=\left\{v \in C:\left\|y_{n}-v\right\| \leq\left\|x_{n}-v\right\|\right\}, \\
D_{n}=\bigcap_{j=1}^{n} C_{j}, \\
x_{n+1}=P_{D_{n}} x, \quad n \geq 1,
\end{array}\right.
$$

where $\left\{\alpha_{n}\right\},\left\{\beta_{n}\right\} \subset[0,1]$. Then the following hold:

(i) If $\liminf _{n \rightarrow \infty} \alpha_{n}>0$ and $\lim _{n \rightarrow \infty} \beta_{n}=0$, then $\left\{x_{n}\right\}$ strongly converges to $x^{\prime} \in F(T)$;

(ii) If $\liminf _{n \rightarrow \infty} \alpha_{n}\left(1-\alpha_{n}\right)>0$ and $\liminf _{n \rightarrow \infty} \beta_{n}>0$, then $\left\{x_{n}\right\}$ converges strongly to $q \in F(S) \cap F(T)$ with $q=P_{F} x$.

Letting $S=I$ in Theorems 2.1 and 2.2, we get the following corollary.

Corollary 2.2 Let C be a nonempty closed convex subset of a Hilbert space H. Let $\left\{T_{i}\right\}_{i=1}^{\infty}$ : $C \rightarrow C$ be a countable family of nonspreading mappings such that $\bigcap_{i=1}^{\infty} F\left(T_{i}\right) \neq \emptyset$. Let $\left\{x_{n}\right\}$ 
be a sequence generated in the following manner:

$$
\left\{\begin{array}{l}
x_{1}=x \in C \quad \text { chosen arbitrarily, } \\
y_{n}=\left(1-\alpha_{n}\left(1-\beta_{n}\right)\right) x_{n}+\alpha_{n} \sum_{i=1}^{n}\left(\beta_{i-1}-\beta_{i}\right) T_{i} x_{n}, \\
C_{n}=\left\{v \in C:\left\|y_{n}-v\right\| \leq\left\|x_{n}-v\right\|\right\}, \\
D_{n}=\bigcap_{j=1}^{n} C_{j}, \\
x_{n+1}=P_{D_{n}} x, \quad n \geq 1
\end{array}\right.
$$

where $\left\{\alpha_{n}\right\},\left\{\beta_{n}\right\} \subset[0,1]$. Assume that $\left\{\beta_{n}\right\}$ is strictly decreasing and $\beta_{0}=1$. Then if $\liminf _{n \rightarrow \infty} \alpha_{n}\left(1-\alpha_{n}\right)>0$, then $\left\{x_{n}\right\}$ strongly converges to $q \in \bigcap_{i=1}^{\infty} F\left(T_{i}\right)$.

Corollary 2.3 Let C be a nonempty closed convex subset of a Hilbert space H. Let $\left\{T_{i}\right\}_{i=1}^{\infty}$ : $C \rightarrow C$ be a countable family of nonspreading mappings such that $\bigcap_{i=1}^{\infty} F\left(T_{i}\right) \neq \emptyset$. Let $\left\{x_{n}\right\}$ be a sequence generated in the following manner:

$$
\left\{\begin{array}{l}
x_{1}=x \in C \quad \text { chosen arbitrarily, } \\
y_{n}=\left(1-\alpha_{n}\left(1-\beta_{n}\right)\right) x_{n}+\alpha_{n}\left(1-\beta_{n}\right) T_{n} x_{n} \\
C_{n}=\left\{v \in C:\left\|y_{n}-v\right\| \leq\left\|x_{n}-v\right\|\right\} \\
D_{n}=\bigcap_{j=1}^{n} C_{j}, \\
x_{n+1}=P_{D_{n}} x, \quad n \geq 1
\end{array}\right.
$$

where $\left\{\gamma_{n}\right\} \subset[0,1]$. Assume that $\left(\left\{T_{n}, T\right\}\right)$ satisfies the AKTT-condition. Then if $\liminf _{n \rightarrow \infty} \alpha_{n}\left(1-\alpha_{n}\right)>0$, then $\left\{x_{n}\right\}$ strongly converges to $q \in \bigcap_{i=1}^{\infty} F\left(T_{i}\right)$.

\section{Competing interests}

The author declares that he has no competing interests.

\section{Authors' contributions}

The author read and approved the final manuscript.

\section{Acknowledgements}

This work is supported by the Fundamental Research Funds for the Central Universities (Grant Number: 13MS109).

Received: 31 August 2013 Accepted: 28 October 2013 Published: 25 Nov 2013

\section{References}

1. Mann, WR: Mean value methods in iteration. Proc. Am. Math. Soc. 4, 506-510 (1953)

2. liduka, $\mathrm{H}$, Takahashi, W: Strong convergence theorems for nonexpansive mappings and inverse-strongly monotone mappings. Nonlinear Anal. 61, 341-350 (2005)

3. Kohsaka, F, Takahashi, W: Fixed point theorems for a class of nonlinear mappings related to maximal monotone operators in Banach spaces. Arch. Math. 91, 166-177 (2008)

4. Matsushita, SY, Takahashi, W: A strong convergence theorem for relatively nonexpansive mappings in a Banach space. J. Approx. Theory 135, 257-266 (2005)

5. Nakajo, K, Takahashi, W: Strong convergence theorems for nonexpansive mappings and nonexpansive semigroups. J. Math. Anal. Appl. 279, 372-379 (2003)

6. Shioji, N, Takahashi, W: Strong convergence theorems for asymptotically nonexpansive semigroups in Hilbert spaces. Nonlinear Anal. 34, 87-99 (1998)

7. Shimizu, T, Takahashi, W: Strong convergence to common fixed points of families of nonexpansive mappings. J. Math. Anal. Appl. 211, 71-83 (1997)

8. Takahahshi, W, Zembayashi, K: Strong and weak convergence theorems for equilibrium problems and relatively nonexpansive mappings in Banach spaces. Nonlinear Anal. 70, 45-57 (2009)

9. Takahashi, S, Takahashi, W: Viscosity approximation methods for equilibrium problems and fixed point problems in Hilbert spaces. J. Math. Anal. Appl. 331, 506-515 (2007)

10. Itoh, S, Takahashi, W: The common fixed point theory of singlevalued mappings and multivalued mappings. Pac. J. Math. 79, 493-508 (1978) 
11. lemoto, S, Takahashi, W: Approximating common fixed points of nonexpansive mappings and nonspreading mappings in a Hilbert space. Nonlinear Anal. 71, 2082-2089 (2009)

12. Moudafi, A: Krasnoselski-Mann iteration for hierarchical fixed-point problems. Inverse Probl. 23, 1635-1640 (2007)

13. Aoyama, A, Kimura, Y, Takahashi, W, Toyada, M: Approximation of common fixed points of a countable family of nonexpansive mappings in a Banach space. Nonlinear Anal. 67, 2350-2360 (2007)

14. Marino, G, Xu, HK: Weak and strong convergence theorems for strict pseudo-contractions in Hilbert spaces. J. Math Anal. Appl. 329, 336-346 (2007)

10.1186/1687-1812-2013-314

Cite this article as: Wang: Hybrid iterative algorithms for nonexpansive and nonspreading mappings in Hilbert spaces. Fixed Point Theory and Applications 2013, 2013:314

Submit your manuscript to a SpringerOpen ${ }^{\circ}$ journal and benefit from:

- Convenient online submission

- Rigorous peer review

- Immediate publication on acceptance

- Open access: articles freely available online

- High visibility within the field

- Retaining the copyright to your article 